\title{
CAVITATION DURING TENSILE DRAWING OF SEMICRYSTALLINE POLYMERS
}

Andrzej Pawlak, Andrzej Gałęski

Centre of Molecular and Macromolecular Studies, Polish Academy of Sciences, Sienkiewicza 112, 90-363 Łódź

e-mail: apawlak@bilbo.cbmm.lodz.pl

andgal@bilbo2.cbmm.lodz.pl

Corresponding author: A. Pawlak 


\title{
CAVITATION DURING TENSILE DRAWING OF SEMICRYSTALLINE POLYMERS
}

\begin{abstract}
The article presents the state of knowledge on the phenomenon of cavitation observed during uniaxial stretching of semicrystalline polymers. Cavitation occurs when the stress at which the amorphous phase breaks is lower than the stress initiating plastic deformation of crystals. The text presents the process of plastic deformation, conditions in which polymers cavitate, with special attention devoted to plastic deformation and cavitation in polyethylene, polypropylene and polyamide.
\end{abstract}

\section{KAWITACJE PODCZAS JEDNOOSIOWEGO ROZCIĄGANIA POLIMERÓW CZESŚCIOWOKRYSTALICZNYCH}

\section{Streszczenie}

W artykule opisany jest stan wiedzy na temat zjawiska kawitacji, obserwowanego podczas deformacji jednoosiowej polimerów częściowokrystalicznych. Do kawitacji dochodzi, gdy naprężenie przy którym rozerwaniu ulega faza amorficzna ma mniejszą wartość niż naprężenie, przy którym zaczyna się deformacja plastyczna kryształów. W tekście omówiono szczegółowo proces deformacji plastycznej i warunki które muszą zostać spełnione aby polimer kawitował. Szczególną uwagę zwrócono na mechanizmy deformacji plastycznej i kawitacji w polietylenie, polipropylenie oraz poliamidzie.

Keywords: plastic deformation, cavitation, polyethylene, polypropylene Słowa kluczowe: deformacja plastyczna, kawitacje, polietylen, polipropylen 


\section{Plastic deformation of semicrystalline polymers}

Good mechanical properties are required in most polymer applications. The possibilities of their control depend on the understanding of the phenomena which occur during deformation. Regardless of many years of studies, the knowledge of deformation mechanisms is still not complete, especially in the case of the most common kind of deformation, i. e. uniaxial stretching. One of the issues to be examined, which is the main subject of this paper, is cavitation during deformation, observed in some polymers under tension.

Plastic deformation of a semicrystalline polymer is a complex process, because different elements of amorphous and crystalline phase participate in it, depending on the level of deformation [1-7]. Macromolecules are entangled in amorphous phase and their fragments are elements of lamellae. As a result, polymer chains form an elastic network. In the polymers crystallized from melt in common conditions the crystalline lamellae frequently form spherulitic structures.

When a polymer is deformed the internal distribution of forces depends on the location within spherulite, therefore deformation is not uniform. Usually the uniaxial tensile test [4-6, 8] provides the source of knowledge about plastic deformation of polymers, however results of other tests, such as uniaxial compression $[9,10]$ or plane strain compression [11-13], are also available. The absolute values of stress and strain parameters may depend on the test type, however the fundamental mechanisms of the polymer's deformation process (the exceptions discussed below) are the same. For this reason, the process of plastic deformation may be presented on the example of uniaxial stretching. 
When the external force is applied to a polymer, it is deformation of amorphous phase which occurs first. This results in the changes in the position (e. g. orientation) of individual lamellae and/or groups of lamellae and interlamellar slips, the slips being the effect of operation of shear forces [4]. The possibilities of such deformation of amorphous phase are limited to macroscopic strains below 10-15\%. Above it, the internal stresses are high enough to initiate chain slips inside the crystalline lamellae, so-called intralamellar slips [7]. Chain slips are the result of a screw dislocation movement. The large number and collectivity of these slips are responsible for the observed macroscopic yield point. The chain slips in crystals may be fine or coarse. Usually at the beginning of plastic deformation fine slips dominate. Later, with an increase in strain coarse slips are observed more frequently. Chain slip is a dominating mechanism in plastic deformation of polymer crystals, but sometimes also two other processes, twinning and phase (martensitic) transformations, are observed $[1,3,8]$.

If a deformed polymer is of a sperulitic structure, then after crossing the yield point elongation of spherulites is observed. The lamellae forming spherulites are linked in a stiff structure and at the beginning of deformation they have only limited possibility of changing position. Moreover, the course of deformation inside the spherulite depends on the location. This is illustrated in Fig. 1, where three significant areas are marked as A, B, C. In the polar zone of a spherulite (A in Fig. 1) the tensile stress component is parallel to lamellar surfaces and is responsible for crystal fragmentation at large strains. If the spaces between broken fragments of lamellae are small, they may be filled with amorphous phase under the influence of the compression component of stress [14].

The diagonal part of a spherulite (marked B) is the place where shear forces operate and interlamellar slips are first initiated [15]. On the spherulite's equator (area C) lamellae are 
perpendicular to the direction of force and the separation of lamellae occurs at the beginning of deformation. Sometimes the undulation of lamellae is observed in this part of a spherulite, because the stress tensor also has a compression component $[15,16]$.

With an increase in deformation intralamellar slips become a widespread phenomenon. Slips result in the appearance of block structures of lamellae, individual blocks having a width of 10-30 nm [17]. When the true strain reaches 0.6 (for PE), lamellar fragmentation begins. Fragmentation does not necessarily mean full disintegration of crystals. At this strain also the first fibrils are formed [18]. Fragmentation of lamellae is related to partial local stress relaxation. Changes in the amorphous phase occurred at this phase of deformation seem to be of smaller significance. Fragments of macromolecules may transfer from crystals into the amorphous phase, and orientation of macromolecules or eventually breaking of bonds in chains may occur that was detected by electron paramagnetic resonance [19].

The studies of relaxation in polyolefins conducted by Strobl's group demonstrated that the chains disentanglement in amorphous phase starts at the true strain of 1.0 or more [18]. The polymer deformation becomes irreversible and the polymer does not return to the initial dimensions after stress relaxation, even if it is annealed at the temperature close to the melting point. Disentanglement process is characteristic of tensile deformation. For plane strain compression it has been observed that the number of entanglements does not change-with deformation $[20,21]$. As a result of the above described phenomena the structure is converted from lamellar into fibrillar, when the macroscopic (engineering) strain is larger than $100 \%$. The process of transformation may be briefly described by Peterlin's model [22].

On the basis of studies of polyethylenes and ethylene copolymers Strobl presented a hypothesis that there exist some characteristic strain values, related to successive deformation mechanisms, which are the same for any polymer $[18,23,24,25]$. The characteristic points A 
to D, as proposed by Strobl, are marked on the stress-strain curve, presented in Fig 2. In these points the following mechanical processes are initiated: A- individual acts of deformation as single lamellar separations; rotations of lamellae and interlamellar slips; B- massive chains slips; C - lamellar fragmentation and beginning of fibrillation; and D - chains disentanglement. It is doubtful if the same characteristic strain values were in force for polymers so much different from polyolefins, e .g. poly(lactide acid) (PLA) or polyethylene terephtalate in which the amorphous phase at room temperature is in a glassy state, and the yield point (B) is reached much earlier than in HDPE. The yield in PLA is often reached at the engineering strain below 5\% [26], while for HDPE the yield strain is $10 \%$ or more.

The above description of plastic deformation does not include an important process, which is observed in many semicrystalline polymers, $\mathrm{i}$.e. cavitation during deformation. The cavities are formed inside the strained amorphous phase. The process of cavitation is rapid and numerous voids are formed. Cavities are of micro- and nanometer size [27-31] and are mainly localized in the part of amorphous phase inside the spherulites [16]. Rozanski et al. [32] showed that the increase of free volume in polymer leads to intensification of cavitation process and it seems that initiation (nucleation) of cavitation is caused by largest free volume fluctuations. The rapid break of polymer structure due to voiding changes the local state of stress and influences further deformation. It seems that the influence of smaller nanocavities on the process of deformation is more important than those of micrometer size, since their number is significantly larger and they disturb the process of deformation on a more fundamental level.

It should be emphasized that voids may also exist in a non-deformed polymer, as a result of its solidification from melt. Previously we studied cavitation phenomena occuring during isothermal crystallization [33-35]. It was demonstrated that due to differences in 
density between the melt and the crystalline phase, negative stress is formed in the places occluded by growing spherulites. The value of the generated pressure depends on the polymer type and on the area of "weak" place. Our measurements showed that the negative pressure for polyethylene is between -3 and $-10 \mathrm{MPa}$ [33]. Negative pressure may lead to the break of melt before solidification or to the formation of stressed areas between spherulites. The cavities formed during isothermal crystallization are of micrometer size.

If the process of crystallization is non-isothermal, spherulites usually grow smaller. Also the pockets of melt occluded between growing spherulites are smaller than during isothermal crystallization and negative pressures are lower. The solidified amorphous phase is stressed but cavitation does not occur during non-isothermal crystallization. Probably, the procedure of crystallization leading to a more or less strained amorphous phase may influence further cavitation during deformation.

However, the main subject of this paper are nanometer cavities, which are formed in the polymer in amorphous layers between crystalline lamellae during tensile deformation.

\section{Cavitation}

Cavitation has been observed in semicrystalline polymers for 20 years. For a long time it has been treated as a marginal phenomenon. Systematic description of voids formation, their evolution and conditions of cavitation has not been published yet. As it is known, voids are formed during uniaxial deformation in crystallizing polymers such as: polyethylene, polypropylene, poly(methylene oxide), poly(ethylene terephtalate), polyamide 6 . The cavitation process depends on the polymer's morphology and deformation conditions [14,2629,36-45].

The cavities in polymers are usually detected by scattering techniques, most often by 
small-angle X-ray scattering (SAXS) [27-31]. Recently, instead of the classical X-ray source the synchrotron radiation has been applied more often $[27,28,30,31,46,47]$. The X-ray radiation allows to detect the holes with a diameter of 2-80 $\mathrm{nm}$. The larger cavities, of micrometer size, scatter the light and the scattering is visible as a whitening of the material [42]. Void formation decreases the density of a polymer, therefore cavitation may be detected by densitometry or by complementary measurements of volume increase [48-52].

Fig. 3 presents mechanical properties of some cavitating (POM, PA 6) and noncavitating (LDPE) polymers and accompanying changes in volume. Cavitation in polymers is characterized by a large volume increase, reaching $30-50 \%$ or more of the initial volume $[45,51]$. This is illustrated in Fig $3 \mathrm{~b}$ on the example of strained poly(methylene oxide) (POM) sample. Fig. 3 also presents that for non-cavitating polymers, like LDPE, the volume is nearly constant.

Sometimes voids are incorrectly identified as crazes. Crazes are usually generated in amorphous polymers (PS, PC), but are also observed in semicrystalline polymers [53-56]. They are voids in which edges are joined by oriented polymer fibrils, and thanks to these ligaments crazes are able to transfer stresses. This is not the case with cavities. The SAXS scattering pattern from crazes has two perpendicular components - from voids and from fibrils, and is therefore different than the pattern from voids [53]. It may be concluded that it is the generation of cavities and not crazing which is typical of deformed crystalline polymers.

The earliest texts which dealt with cavitation were published in the seventies of the last century. These papers mostly focused on the morphological changes during deformation, not on cavitation. As example, Keller and Pope studied the oriented LDPE and observed an increase in SAXS scattering with an increase in interlamellar distances [57]. Clark, in turn, noted an increase in volume of the deformed polymer [58]. These facts were interpreted as an 
effect of cavitation between those lamellae whose surfaces were oriented perpendicularly to the direction of deformation [3]. The larger cracks, of a few micrometers width, were observed by Peterlin [8] and Jang [56], inside the spherulites and on the border between spherulites. In some cracks, located inside the spherulites, fragments of the deformed polymer were visible, so they were wrongly interpreted as crazes [56]. The above observations concerned late stages of the deformation process.

One of the early papers, linking deformation mechanisms to the accompanying volume changes, was the work by Cessna [51]. He noted that when polypropylene is deformed rapidly $(20 \mathrm{~m} / \mathrm{min})$ or at very low temperatures $\left(-190{ }^{\circ} \mathrm{C}\right), 30-40 \%$ volume increase occurs before the break, probably as a result of voiding or crazing. Stein and co-workers analyzed X-ray scattering from HDPE specimens tested in the deformation oscillations mode and in cold drawing. They concluded that in the second case the anisotropic cavities were formed at the strain of $10 \%$. The observed voids were initially oriented perpendicularly to the direction of deformation, but next they reoriented [59].

Galeski et al. examined the morphology of deformed polyamide, contrasted with $\mathrm{OsO}_{4}$ and sliced. They stated that traces of the previously existing cavities were visible in different positions inside the spherulites, marked by the broken chemical bonds [15]. The analysis of position of places which reacted with $\mathrm{OsO}_{4}$ led to the conclusion that the cavities were formed in the equatorial parts of spherulites, between the folded (undulated) lamellae and in the polar parts, between the broken lamellae.

In the period of 1995-1998 the group led by Butler published a cycle of three papers on the mechanical properties of polyolefins $[27,28,47]$. They observed that voiding occurred at the beginning of plastic deformation. Simultaneous SAXS and WAXS in-situ measurements during uniaxial stretching demonstrated that cavities in HDPE appeared close 
to the yield point, exactly at the moment of martensitic transformation of some crystals [47]. Another interesting observation was that in linear low density polyethylene (LLDPE), characterized by thinner crystals, martensitic transformation also occurs, but without cavitation. The second paper showed that oval scattering pattern from cavities changes orientation at the engineering strains larger than $30 \%$ [27]. It was also observed that whitening due to cavitation occurs around the yield point. More intensive X-ray scattering was from cavities in polyethylene characterized by lower molecular weight [28].

Similar, simultaneous X-ray and tensile studies of polyethylene were conducted by Hughes et al. [30], but the strain rate was higher $\left(3 \mathrm{~s}^{-1}\right)$ in this case. It was confirmed that cavities are formed at the yield and that whitening of samples accompanies cavitation. Authors suggest that voids are formed in the spherulite's equator and that the cavities are initially elongated perpendicularly to the direction of deformation. The voids reorient with an increase in deformation or the new ones are generated, but oriented in the direction of deformation.

There are many works which concern cavitation in polypropylene. Liu et al. [42] confirmed Cessna's [51] observation that whitening due to cavitation occurs when the draw ratio is fast or the testing temperature is low. Microscopic examination by scanning electron microscopy (SEM) showed that whitening is in microscale accompanied by voids, located between fibrils. Similar voids were not observed in the other samples, for which whitening did not occur. Their second observation was that the X-ray diffraction peaks from crystalline phase were wider in the cavitating samples, which means that fragmentation of crystals occurred into smaller blocks.

Another group from Korea [43] noticed that if polypropylene is simultaneously kept under hydrostatic pressure during deformation, then whitening and cavitiation are not present. 
Yamaguchi and Nitta [44] measured light transmittance for PP samples and concluded that whitening is visible at yield (i. e. for strain of $15 \%$ ), however a decrease in transmittance begins much earlier, at the engineering strain of $7 \%$.

Zhang and co-workers [60] studying mechanisms of plastic deformation in the samples previously exposed to gamma radiation from ${ }^{60} \mathrm{Co}$ source, observed that radiated PP cavitates shortly before yield point, if the temperature is below $60^{\circ} \mathrm{C}$. They concluded that voiding precedes a massive break of lamellar crystals and that the formation of voids is a necessary precursor of chains slips when macromolecular chains in amorphous phase have limited mobility or when shear inside the crystal is difficult due to low temperature or considerable thickness of crystals.

Changes in volume in many deformed polymers were the subject of studies conducted by G'Sell's group $[45,48,49]$. An example of homopolymer characterized by a large increase in volume is poly(ethylene terephtalate). The microscopic analysis showed that in PET two mechanisms of deformation are present: shear bands and crazes [48]. Long crazes, with the length of around $100 \mu \mathrm{m}$, were responsible for the volume increase in these polymers. In the other of the examined polymers, poly(vinylidene fluoride), the analyzed volume was disturbed by two processes: nucleation of cavities before yield and growth of cavities during further deformation [61]. A large increase in volume, up to 40\%, was observed by G'Sell for polypropylene and polyethylene [45,49]. Billon [62] made a similar observation for the injected PP specimens. Na et al. [63] discovered that the solid state annealing lead to an increase in volume during tensile deformation, both in isotactic polypropylene and in nucleated PP, containing mostly $\beta$ phase crystals [64].

In the recent years a few papers have been published which discussed plastic deformation and the effect of cavitation in which synchrotron radiation was applied for 
detection of cavities. These included, among others, the articles by Schneider et al. [31] and Jiang et al. [46]. Schneider analyzed disc-shaped HDPE samples, in which deformation was localized by notching. As in the case of earlier works, cavities were visible starting from yield and their shape changed with deformation. The analysis of SAXS profiles led to the conclusion that the content of the voids' fractions does not change during the hardening phase of deformation, however the size of voids changes with the strain level.

It is commonly known that if a polymer has a spherulitic structure, then cavities are formed at yield in the equatorial belt of a spherulite, where lamellar surfaces are perpendicular to the direction of stretching and where the amorphous phase is highly stretched [15] (see Fig. 1). The fact that cavitation is in places located close to the equator was confirmed by atomic force microscopy studies [16]. On the other hand, in the scanning electron microscopy more visible are cavities formed as a result of breaking of lamella in the polar fans of spherulites $[15,65]$. Figure 4 is the illustration of this fact for polypropylene. According to expectations voids are not observed in the diagonal part of spherulites, under $45^{\circ}$ to the direction of deformation (point $\mathrm{C}$ in Fig. 4), where shear dominates. The number of cavities increases with the degree of deformation. When strains are larger then the lamellar - fibrillar transformation takes place according to Peterlin's micronecking model [66]. It appeared later that Peterlin's model requires voiding as a necessary condition for transformation, even if deformation earlier occurred without cavitation. The cavities in the final phase of stretching have recently been observed by G'Sell [67].

Our examinations of the following polymers: low density polyethylene (LDPE), ethylene-octene copolymer (EOC), high density polyethylene (HDPE), polyamide 6 (PA), polypropylene (PP), and poly(methylene oxide) (POM) showed that most of these polymers cavitate during uniaxial stretching, with the exception of LDPE and EOC [40]. The same 
polymers never cavitated during compression in the plane strain conditions. Careful analysis of experimental results lead to the conclusion that the cavities are generated when the local 3D extensional stresses exceed the strength of amorphous phase, but are smaller than the stresses needed for plastic deformation of crystals. For this reason cavities were visible in polymers (POM, PP, HDPE) characterized by large, weakly defected crystals. In the case of polymers with thin and defected crystals the plastic deformation of crystals by chain slips was easier to initiate than the break of amorphous phase. Hence, in our experiments LDPE and EOC did not cavitate. In the stress-strain measurements the polymers able to cavitate are characterized by a larger yield stress (see Fig. 3a), because the yield stress increases with the thickness of lamella and with the reduction of the number of defects in crystals.

The 3D stress is important in cavitation of semicrystalline polymers, and we may learn that, for example, from the studies by Castagnet et al. [68] The three-dimensional tensile stresses are not present in the compressed polymers, so amorphous phase does not break. Comparison of the true stress-true strain curves for the uniaxially stretched and the plane strain compressed polymers shows that there are differences between test results. The stresses in compression at the same strain are larger than the stresses in tension. The difference is small if the polymer does not cavitate, but large for those which cavitate [40].

One of the studied polymers, polyamide, has exhibited untypical behavior. The character of the stress-strain dependence suggested formation of voids during the tensile test, but both X-ray and light scattering observations did not confirm this hypothesis. Estimations based on surface energy and thickness of amorphous layer showed that negative pressure, preventing closing of $5.6 \mathrm{~nm}$ size cavities by surface tension, is for polyamide equal to -33.6 $\mathrm{MPa}$. This pressure is larger than the pressure generated at yield around the void, which is equal to -28.0 MPa. It means that the voids are formed in polyamide, but they are non stable 
and vanish easily during deformation. This is in accordance with the previous observations by Galeski concerning the chains break in some areas of the deformed polyamide, where cavities were not directly visible [15]. Similar calculations for cavitating polymers (i. e. PP, POM, HDPE) showed that in these polymers local stresses exceed the cavitation's stability level, so the cavities do not vanish [40].

The conclusion about existing competition between two possible processes cavitation and plastic deformation of crystals, was based on comparison of behavior for different polymers deformed by stretching. However, if it is true it should be possible to observe in one selected polymer both cavitational and non cavitational behavior, depending on their morphology or testing condition. The aim of further experiments, done in our laboratory and described below was to analyze the influence of different morphological factors and experimental parameters on occurring of cavitation.

\section{$\underline{\text { Recapitulation of recent results from our laboratory }}$}

Two subsequent sections are the synthesis and recapitulation of recent results from our laboratory, published in years $2007-2010$ [14,41,69,70,71]. In these sections we discuss the role of morphology and experimental conditions on cavitation, respectively. The examined materials were limited to polyolefins: high density polyethylene and polypropylene (see Table I). Detailed descriptions of experiments may be found in $[41,69,70]$.

\section{a) Influence of sample morphology on cavitation process.}

Two factors which influences morphology of semicrystalline polymers formed from melt are the cooling procedure and existence or non existence of orientation (stretching or 
shearing) forces in melt during processing. Orientation of lamellae can be an example of a morphological factor favoring cavitation, existing for instance in the surface layer of an injected HDPE bar [41]. The observation conducted by scanning electron microscopy (see Fig. 5) indicated that in such a surface layer crystals are oriented perpendicularly to the direction of deformation (and injection) on the distance up to $300 \mu \mathrm{m}$ from the surface. When the external force is applied, cavities in the surface layer are generated already at the strain of 0.0015 and the stress of $2 \mathrm{MPa}$. However, the cavities in the core of the same sample are generated much later, after yield, at true stress of $29 \mathrm{MPa}$ and strain of 0.3 . The reason for early cavitation in skin is strong localization of deformation in amorphous layers between regularly displaced crystals.

The thickness of crystals and the number of defects in their structure, limiting strength to plastic deformation, depends on the process of crystallization from melt. We examined HDPE samples cooled from the molten state in various manner in air, in water and in iced water. The studies showed that the cavitation did not occur in the sample that solidified most quickly, i. e. in water with ice, in which crystals were thinnest $(19.7 \mathrm{~nm})$. Limited cavitation was observed in a polymer cooled in water, where crystals had the thickness of $20.6 \mathrm{~nm}$, however very intensive cavitation was noted in HDPE cooled in air, where the thickness of crystals was $24.3 \mathrm{~nm}$. The yield stress, which is related to crystal perfection, was equal to 19 , 21 and $26 \mathrm{MPa}$ respectively [41].

Figure 6 presents typical SAXS patterns registered in-situ during tensile deformation of HDPE. The elongated shape of scattering pattern indicates that cavities in polymers are initially ellipsoidal and oriented perpendicularly to the direction of deformation. Their dimensions are not uniform and start from a few nanometers. Usually the SAXS patterns show the presence of 2-4 populations of voids, characterized by different values of 
gyration radius $R_{g}$ [72]. For example, the radii of gyration for a polyethylene sample with the local strain of 0.3 were equal to 4 and $11 \mathrm{~nm}$ [41]. This allows to assume that the axes of ellipsoid describing larger voids, one with $\mathrm{R}_{\mathrm{g}}=11 \mathrm{~nm}$, were 48 and $7 \mathrm{~nm}$. The voids' size increase with an increase in deformation. We observed that when the local strain in HDPE was equal to 1.4 , which is related to the engineering strain of $35 \%$, the gradual reorientation of voids into the direction of deformation occurred, followed by further elongation at large strains. The wide angle X-ray scattering studies (WAXS) showed that the changes in the voids' shape are forced by reorientation of crystals surrounding the amorphous phase [41]. X-ray scattering measurements do not provide quantitative estimations of the scale of the cavitation phenomenon. However, if the dimensions of the sample are measured during deformation, for example by video recording, it is possible to determine the volume changes as a function of deformation $[45,52,73]$. Cavitation is responsible for nearly an entire increase in volume and thus the increase is the measure of the voiding scale. The experiments for HDPE specimens cooled in air showed that their volume increased significantly, even up to $100 \%$ for the local strain $\varepsilon=7$ [41]. If a polymer does not cavitate, the changes in volume are usually small [67]. Our recent studies of isotactic polypropylene samples having different amounts of $\alpha$ and $\beta$ crystals showed that the volume in deformed polymer containing $90 \%$ of $\beta$ crystals may increase even $200 \%$ [71]. The intensity of SAXS scattering from voids is for $\beta$ form reach PP samples three times more than intensity of scattering from usual $\alpha$ form polypropylene. However, the cavitation process, i. e. the moment of initiation, evolution of cavities shape and void's sizes, characterized by radius of gyration, were similar in both crystalline forms of polypropylene.

One of the factors influencing cavitation process via morphology modification is molecular mass. We examined two polypropylenes with different molecular mass, of $4.0^{*} 10^{5}$ 
$\mathrm{g} / \mathrm{mol}$ and $2.5^{*} 10^{5} \mathrm{~g} / \mathrm{mol}$, but with similar crystalline phase, i. e. characterized by the similar degree of crystallinity and crystal thickness. The voids were more numerous in the polymer with the lower molecular mass, where the amorphous phase was weaker and less entangled [14].

We showed the influence of the local morphology on cavitation on the example of deformation of thick injected polypropylene specimens. Examination by polarized light microscopy indicated that the structure of the injected sample depends on the position in volume, as result of different heat withdrawal during solidification. In the center large, 20-30 $\mu \mathrm{m}$ size, spherulites were formed. The closer to the surface, the number and the size of the spherulites decreased. In the skin layer spherulites were not observed, but only small crystalline structures. We expected that cavitation in such a gradient structure would first occur in the center, as confirmed by the SAXS studies. The voids were not detected in the skin layer of the specimen, even at the local strain equal to 2.6 [14].

The morphology of a polymer may be modified by annealing in the solid state, which leads to the thickening of crystals and increase in crystallinity. We examined HDPE samples initially crystallized in such as manner that they do not cavitate at normal testing conditions. If the same material was annealed $3 \mathrm{~h}$ at $\mathrm{T}=125^{\circ} \mathrm{C}$, the number of the defects in the thicker crystals reduced, and the break of amorphous phase became easier than initiation of crystals slips and the polymer cavitated after annealing [69].

\section{b) Influence of experimental factors on cavitation process.}

Apart from morphological factors also testing conditions such as deformation rate and temperature influence the cavitation process, because the sensitivity of amorphous and crystalline phase on changes of experimental conditions is different. As mentioned earlier, 
polyolefins (PP, PE) cooled quickly from melt have small, defected crystals and do not cavitate after yield when tested at the typical rates of $8.3 * 10^{-4}-3.3 * 10^{-3} \mathrm{~s}^{-1}$ [14]. However, if the deformation rate for PP sample is increased to $8.3^{*} 10^{-3} \mathrm{~s}^{-1}$, then the yield stress increases form 35 to $38 \mathrm{MPa}$ and the polymer begins to cavitate. The presence of cavitation was confirmed by a rapid increase in volume in the deformed sample, visible at the strain of 0.15 and more [14]. The opposite situation is observed for PP samples, which were previously solidified by cooling melt in the air. These specimens cavitate when they are deformed at rate of $8.3 * 10^{-4} \mathrm{~s}^{-1}$ and higher. We searched for the rate below which cavitation will be suppressed and it happened at the deformation rate of $0.8^{*} 10^{-5} \mathrm{~s}^{-1}$. Figure 7 presents SAXS patterns for PP samples deformed to engineering strain of $25 \%$ at different strain rates: $1.6 * 10^{-4} \mathrm{~s}^{-1}, 0.8 * 10^{-5}$ $\mathrm{s}^{-1}$ and $5^{*} 10^{-6} \mathrm{~s}^{-1}$, respectively. Yield stress for polypropylene at such test conditions was 28,26 and $24 \mathrm{MPa}$, respectively. Yield strain for all samples was equal 15\%. The cavitation was invisible for slower test. These results, not published previously, were confirmed by volume strain measurement, which does not show increase of volume for slowly and very slowly deformed samples.

Voiding in polymers also depends on the testing temperature. The studies of commercial polypropylene Novolen $1100 \mathrm{~N}$ by BASF showed that a polymer which cavitates at the temperature of 20 and $40{ }^{\circ} \mathrm{C}$ does not cavitate when the temperature is increased to 70 ${ }^{\circ} \mathrm{C}$, because the barrier for initiation of plastic deformation of crystals decreases with temperature [70]. Similar studies of HDPE deformed with the rate of 5\%/min at elevated temperatures, in range of $20-75^{\circ} \mathrm{C}$, showed that in this polymer the yield stress quickly decreases with temperature from $27 \mathrm{MPa}$ at $20^{\circ} \mathrm{C}$ to $19 \mathrm{MPa}$ at $40{ }^{\circ} \mathrm{C}$ and only $9 \mathrm{MPa}$ at 75 ${ }^{\circ} \mathrm{C}$. The whitening of this material was observed at temperatures of deformation up to $32{ }^{\circ} \mathrm{C}$, but not at the higher temperatures. SAXS studies of deformed samples showed that some 
limited cavitation occur at $\mathrm{T}=40^{\circ} \mathrm{C}$, but the cavities are not detected when the temperature of sample was $50{ }^{\circ} \mathrm{C}$ and more. The above observations of cavitation in HDPE deformed at elevated temperatures were not published previously.

\section{CONCLUSIONS}

The cavitation is observed in many semicrystalline polymers deformed in tension, but never in compression. The reason is that $3 \mathrm{D}$ negative pressure should be generated for breaking structure of amorphous phase. The cavities are formed around yield point, at the moment when the intensive plastic deformation of crystals begin. It is the competition between two possible processes: generation of cavitation and initiation of plastic deformation of crystals. If the strength of amorphous phase is lower than yield stress of crystals deformation than the voids are formed at yield. In opposite situation, which happens when the crystals are thin and defected, the plastic deformation of lamellae occurs without cavitation.

The formation of cavities changes rapidly local state of stress and by this promotes further deformation and fragmentation of crystals. It means that cavitation is an important element of deformation process. It is possible, by modifying polymer morphology or deformation conditions, to control the scale of cavitation. It was shown for polypropylene and polyethylene that if the crystallization process is rapid and larger numbers of defects are generated in crystals then such polymers do not cavitate. Also increasing the test temperature or decreasing of the straining rate leads to deformation without cavitation. 


\section{Acknowledgments:}

The study was supported by a grant of MNiSW No. N N508 468834. We wish to express thanks to the Hamburg Synchrotron Radiation Laboratory for the beam time granted within the project I 20090069 EC.

\section{Literature:}

1. Galeski A.: Prog. Polym. Sci. 2003, 28, 1643.

2. Oleinik E.: Polym. Sci. Ser. C 2003, 45, 17.

3. Lin L., Argon A. S.: J. Mat. Sci. 1994, 29, 294.

4. Zhou H., Wilkes G. L., J. Mater. Sci. 1998, 33, 287.

5. Bowden P. B., Young R. J.: J. Mater. Sci. 1974, 9, 2034.

6. Peterlin A.: Coll. Polym. Sci. 1987, 265, 357.

7. Seguela R.: e-Polymers 2007, no. 032.

8. Peterlin A., in: Advances in Polymer Science and Engineering, Proceedings of the Symposium on Polymer Sciences and Engineering, Plenum Press, New York 1972, pp $1-19$.

9. Staniek E., Seguela R., Escaig B., Francois P.: J. Appl. Pol. Sci. 1999, 72, 1241.

10. Bartczak Z., Cohen R., Argon A.: Macromolecules 1992, 25, 4692.

11. Bartczak Z., Argon A., Cohen R.: Polymer 1994, 35, 3427.

12. Galeski A., Bartczak Z., Argon A.S., Cohen R.E.: Macromolecules 1992, 25, 5705.

13. Pluta M., Bartczak Z., Galeski A.: Polymer, 2000, 41, 2271.

14. Pawlak A., Galeski A.: Macromolecules 2008, 41, 2839.

15. Galeski A., Argon A. S., Cohen R. E.: Macromolecules 1988 ,21, 2761.

16. Thomas C., Ferreiro V., Coulon G., Seguela R.: Polymer 2007, 48, 6041.

17. Friedrich, K in: Advances in Polymer Sciences, vol. 52/53; Kausch H.H. Ed; Springer: 
Berlin 1983, pp. 225-274

18. Hiss R., Hobeika S., Lynn C., Strobl G.: Macromolecules 1999, 32, 4390.

19. Campbell D., Peterlin A.: J. Polym. Sci. B 1968, 6, 481.

20. Schonherr H., Vancso G. J., Argon A. S.: Polymer 1995, 36, 2115.

21. Cassagnau P., Montfort J.P., Martin G., Monge P.: Rheolog. Acta 1993, 32, 156.

22. Peterlin A.: J. Mater Sci. 1971, 6 , 490.

23. Hobeika S., Men Y., Strobl G.: Macromolecules 2000, 33, 1827.

24. Fu Q., Men Y., Strobl G.: Polymer 2003, 44, 1941.

25. Hong K., Rastogi A., Strobl G.: Macromolecules 2004, 37, 10165.

26. Piorkowska E., Kulinski Z., Gadzinowska K.: Polimery 2009, 54, 83.

27. Butler M. F., Donald A. M., Ryan A. J.: Polymer 1997, 38, 5521.

28. Butler M. F., Donald A. M., Ryan A. J.: Polymer 1998, 39, 39.

29. Castagnet S., Girault S., Gacougnolle J. L., Dang P.: Polymer 2000, 41, 7523.

30. Hughes D. J., Mahendrasingam A., Oatway W. B., Heeley E. L., Martin C., Fuller W.: Polymer 1997, 38, 6427.

31. Schneider K., Trabelsi S., Zafeiropoulos N. E., Davies R., Riekel Ch., Stamm M.: Macromol. Symp. 2006, 236, 241.

32. Rozanski A., Galeski A., Debowska M.: Macromolecules 2011, 44, 20.

33. Piorkowska E., Galeski A.: J. Polym. Sci. B-Polym. Phys. 1993, 31, 1285.

34. Nowacki R., Kolasinska J., Piorkowska E.: J. Appl. Polym. Sci. 2001, 79, 2439.

35. Nowacki R., Piorkowska E.: J. Appl. Polym. Sci. 2007, 105, 1053.

36. Duffo P., Monasse B., Haudin J. M., G’Sell C., Dahoun A.: J. Mater. Sci. 1995, 30, 701.

37. Nathani H., Dasari A., Misra R. D. K.: Acta Mater. 2004, 52, 3217.

38. Li J. X., Cheung W. L.: Polymer 1999, 40, 2089.

39. Gencur S. J., Rimnac C. M., Kurtz S. M.: Biomaterials 2003, 24, 3947.

40. Pawlak A., Galeski A.: Macromolecules 2005, 38, 9688.

41. Pawlak A.: Polymer 2007, 48, 1397.

42. Liu Y., Truss R. W.: J. Polym. Sci., B. Polym. Phys. 1994, 32, 2037.

43. Pae K. D., Chiu H-C., Lee J. K., Kim J-H.: Polym. Eng. Sci. 2000, 40, 1783.

44. Yamaguchi, M., Nitta, K.-H.: Polym. Eng. Sci. 1999, 39, 833.

45. G'Sell Ch., Bai S.-L., Hiver J.-M.: Polymer 2004, 45, 5785. 
46. Jiang Z., Tang Y., Men Y., Enderle H.-F., Lilge D., Roth S. V., Gehrke R., Rieger J.: Macromolecules 2007, 40, 7263.

47. Butler M. F., Donald A. M., Bras W., Mant G. R., Derbyshire G. E., Ryan A.J.: Macromolecules 1995, 28, 6383.

48. G'Sell C., Hiver J. M., Dahoun A.: Int. J. Solids and Struct. 2002, 39, 3857.

49. Addiego F., Dahoun A., G’Sell C., Hiver J. M.: Polymer 2006, 47, 4387.

50. Lazzeri A., Thio Y. S., Cohen R. E.: J. Appl. Polym. Sci. 2004, 91, 925.

51. Cessna L. C.: Polym. Eng. Sci 1974, 14, 696.

52. Naqui S. I., Robinson I.M.: J. Mat. Sci. 1993, 28, 1421.

53. Brown H. R., Kramer E. J.: J. Macromol. Sci. Phys. 1981, B19, 487.

54. Mills P.J., Kramer E. J.: J. Mater. Sci. 1985, 20, 4413.

55. Zafeiropoulos N. E., Davies R. J., Schneider K., Burghammer M., Riekel Ch., Stamm M.: Macromol. Rapid Commun. 2006, 27, 1689.

56. Jang B. Z., Uhlmann D. R., Vander Sande B. J.: Polym. Eng. Sci. 1985, 25, 98.

57. Keller A., Pope D. P.: J. Mater. Sci. 1971, 6, 453.

58. Garber C. A., Clark E. S.: J. Macromol. Sci. Phys. 1970, B4, 499.

59. Young P., Kyu T., Suehiro S., Lin J. S., Stein R. S.: J. Polym. Sci. Polym. Phys. Ed. $1983,21,881$.

60. Zhang X. C., Butler M. F., Cameron, R. E.: Polymer 2000, 41, 3797.

61. Quatravaux T., Elkoun S., G'Sell C., Cangemi L., Meimon Y.: J. Polym. Sci. B Polym. Phys. 2002, 40, 2516.

62. Temimi N., Burr A., Billon N. in: Book of Abstracts. Euromech Colloquium 487. Structure Sensitive Mechanics of Polymer Materials: Physical and Mechanical Aspects. Strasbourg 10-13.10.2006; Remond Y., Patlazhan S. Eds; Strasbourg 2006, pp. 67-68.

63. Na B., Lv R.: J. Appl. Polym. Sci. 2007, 105, 3274.

64. Lv R., Xu W., Na B., Yan J.: J. Appl. Polym. Sci. 2008, 108, 3185.

65. Dijkstra P. T. S., Van Dijk D. J., Huetnik J: Polym. Eng. Sci. 2002, 42, 152-160.

66. Peterlin A. Plastic deformation of crystalline polymers in: Polymeric Materials, Baer E., Ed., American Society for Metals: Metals Park, Ohio, 1975, pp. 175-195.

67. Addiego F., Dahoun A., G'Sell C., Hiver J. M., Godard O.: Polym. Eng. Sci. 2009, 49, 1198. 
68. Castagnet S., Deburk Y.: Mater. Sci. Eng. 2007, A 448, 56.

69. Pawlak A., Galeski A.: Polymer 2010, 51, 5771.

70. Pawlak A., Galeski A.: J. Pol. Sci. B: Pol. Phys. 2010, 48, 1271.

71. Pawlak A.: J. Appl. Polym. Sci. (in print)

72. Yamashita T., Nabeshima Y.: Polymer 2000, 41, 6067.

73. Powers J. M., Caddell R. M.: Polym. Eng. Sci. 1972, 12, 432. 
Table I. Polymers used in the studies of cavitation.

\begin{tabular}{|l|l|l|l|}
\hline Polymer & $\begin{array}{l}\text { Molecular mass } \\
\mathrm{M}_{\mathrm{w}}(\mathrm{g} / \mathrm{mol})\end{array}$ & $\mathrm{M}_{\mathrm{w}} / \mathrm{M}_{\mathrm{n}}$ & $\begin{array}{l}\text { Melt Flow Index }(\mathrm{g} / 10 \\
\text { min) }\end{array}$ \\
\hline $\begin{array}{l}\text { HDPE Lupolene } \\
\text { 6021D (BASF) }\end{array}$ & $1.8^{*} 10^{5}$ & 7.2 & 0.26 \\
\hline $\begin{array}{l}\text { PP Novolen 1100H } \\
\text { (BASF) }\end{array}$ & $4.0^{*} 10^{5}$ & 5.0 & 1,8 \\
\hline $\begin{array}{l}\text { PP Novolen 1100N } \\
\text { (BASF) }\end{array}$ & $2.5^{*} 10^{5}$ & 5.0 & 11.0 \\
\hline $\begin{array}{l}\text { PP Malen P } \\
\text { F 401 (Basell } \\
\text { Orlen) }\end{array}$ & $3.0^{*} 10^{5}$ & 5.3 & 3.0 \\
\hline
\end{tabular}

*Testing conditions: $2.16 \mathrm{~kg}, 190^{\circ} \mathrm{C}$ (HDPE) or $2.16 \mathrm{~kg}, 230{ }^{\circ} \mathrm{C}$ (PP) 


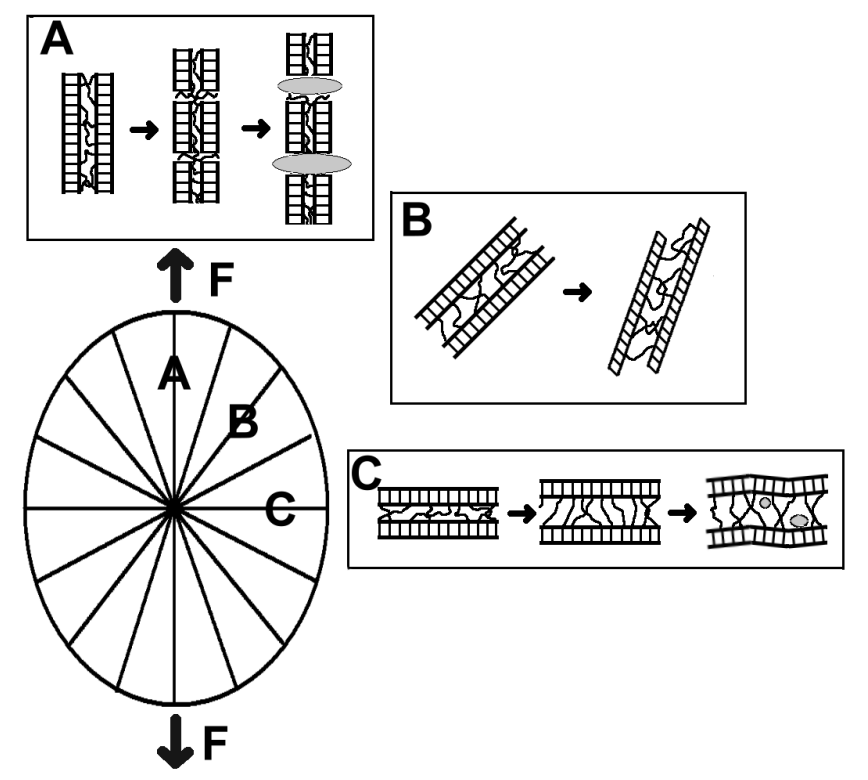

Fig. 1. Schematic of spherulite's deformation in tension. Details of lamellar deformation in the polar part (A), under the angle $45^{\circ}(\mathrm{B})$ and in the equatorial part of the spherulite $(\mathrm{C})$ are presented.

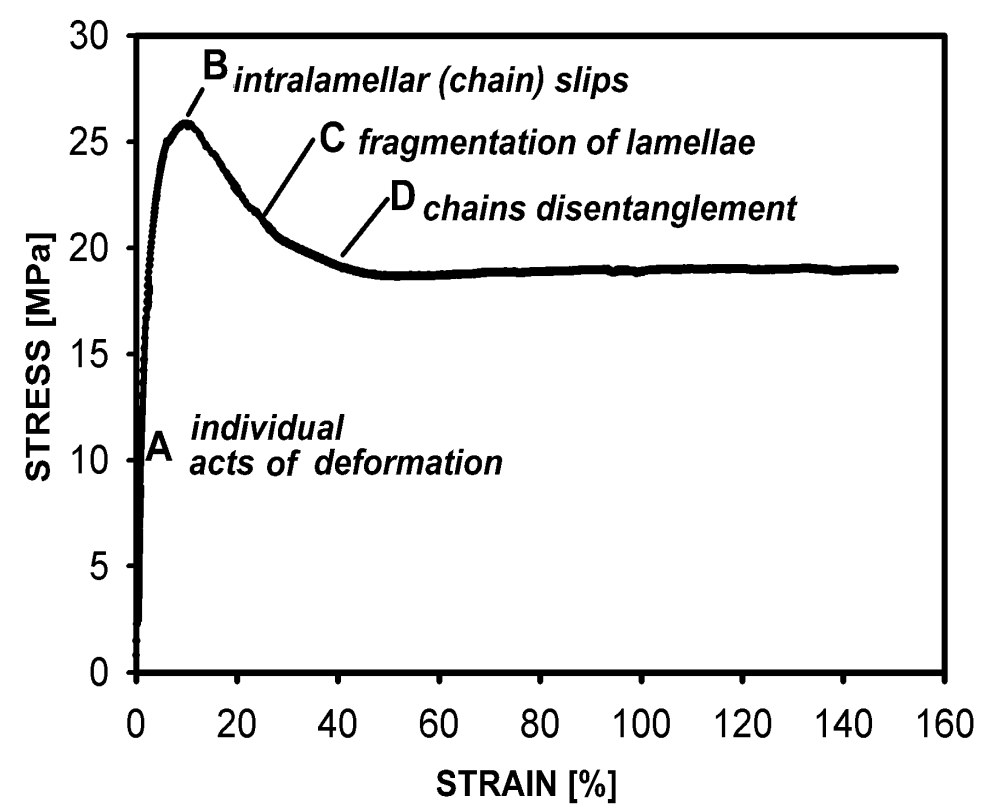

Fig. 2.The stress-strain dependence for HDPE sample deformed at the strain rate of $5 \% / \mathrm{min}$.

Strobl's characteristic points of deformation [18] are marked as A-D. 

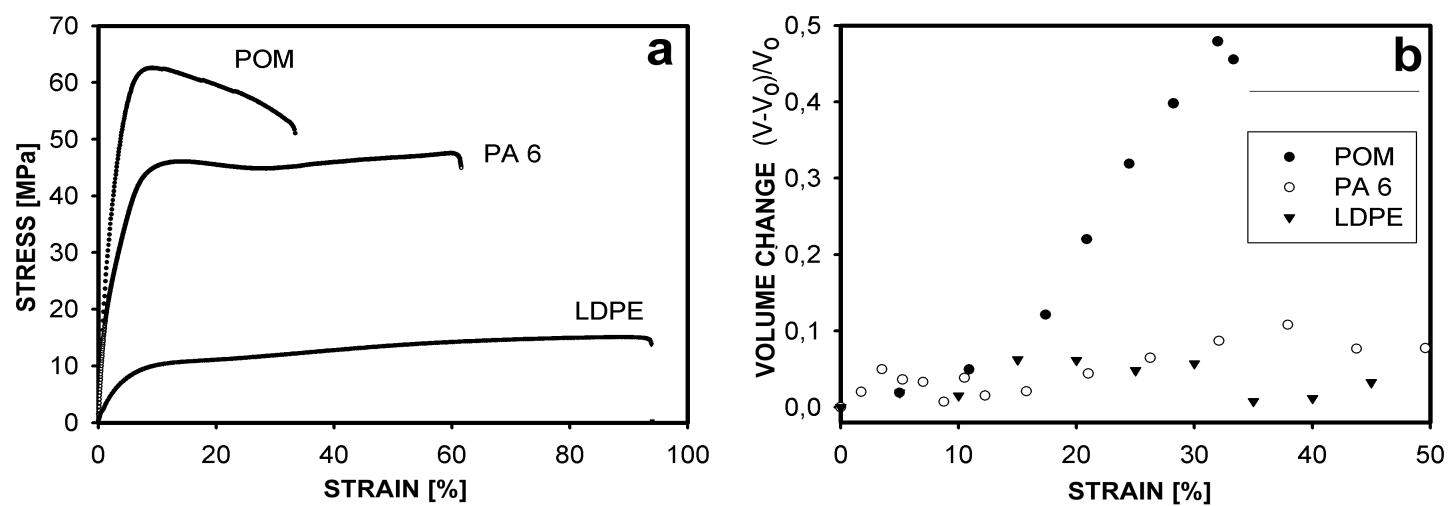

Fig 3. Mechanical properties of selected polymers in tension (a) and related volume changes (b).

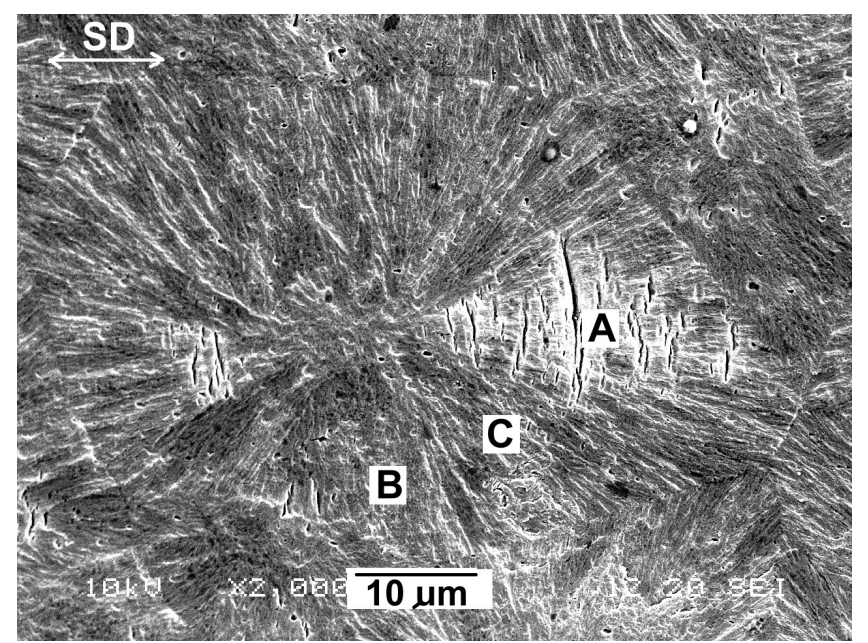

Fig 4. Deformed spherulite of polypropylene observed by SEM. The direction of deformation was horizontal. A - polar fan, B- equatorial area, C - diagonal, shear area, without cavities. $\mathrm{SD}$ - strain direction. 


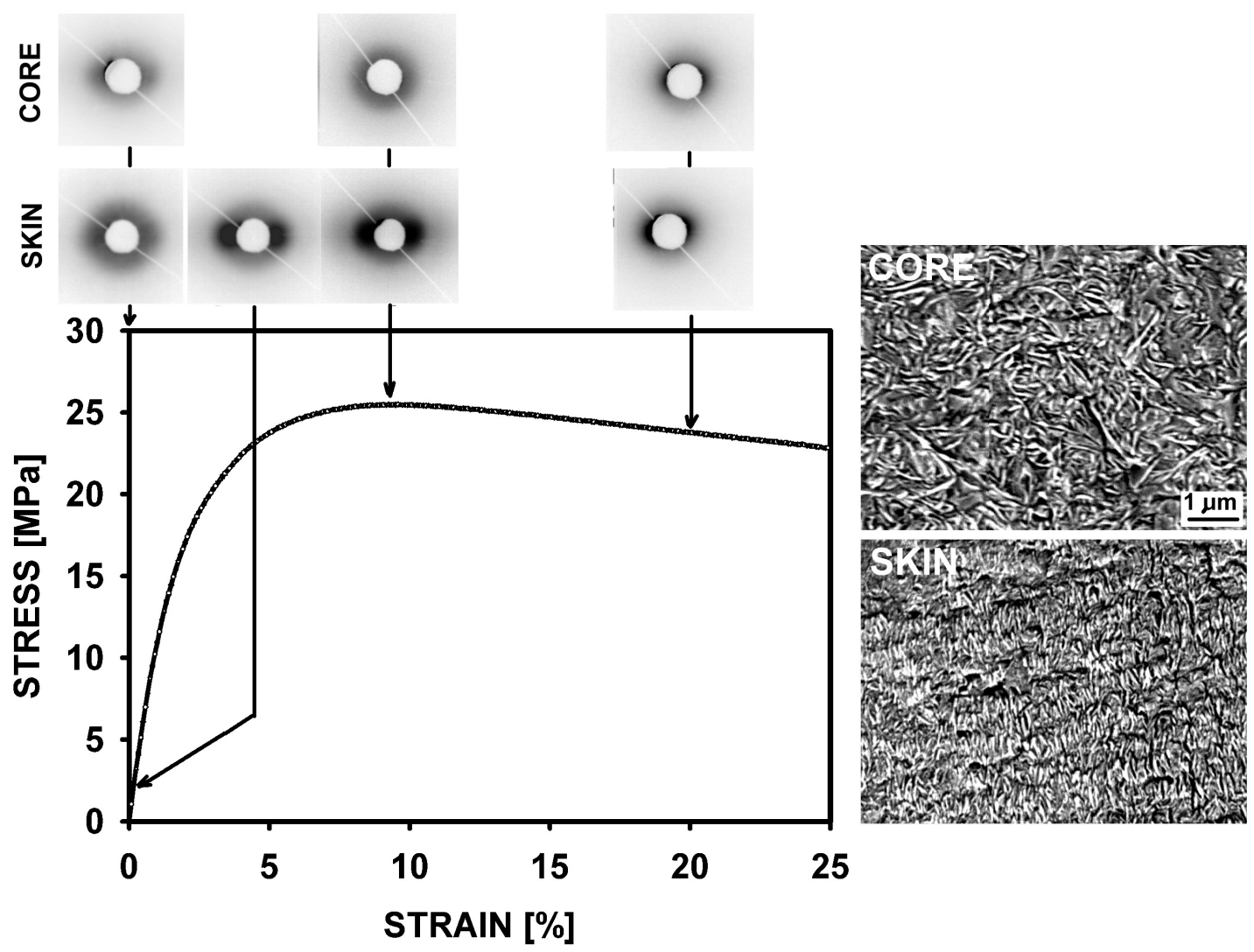

Fig. 5. Engineering stress-strain curve for injection molded HDPE and SAXS patterns

registered for skin and core of sample (top). The morphology of skin and core is shown on

SEM photographs (right). This figure is based on the data from the studies described in [41]. 


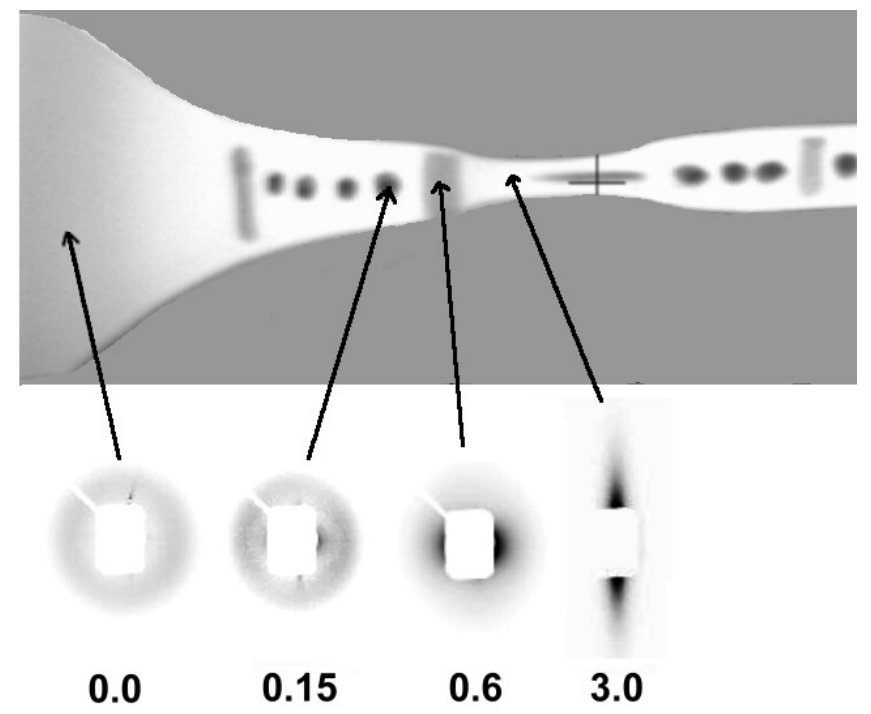

Fig 6. The photography of deformed HDPE sample and SAXS patterns, as registered in situ by applying synchrotron radiation. Arrows indicate the places where patterns were registered, the numbers show local strain. Scattering on voids is clearly visible for strains of 0.6 and 3.0, and some traces are observed for the strain of 0.15 .

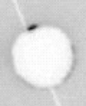

a

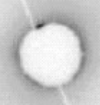

b

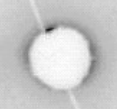

C

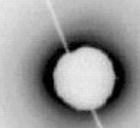

d

Fig. 7. SAXS patterns for PP samples deformed to engineering strain of $25 \%$ at different strain rates: a) non deformed, b) $5^{*} 10^{-6} \mathrm{~s}^{-1}$, c) $0.8^{*} 10^{-5} \mathrm{~s}^{-1}$, d) $1.6^{*} 10^{-4} \mathrm{~s}^{-1}$. 


\section{FIGURE CAPTION}

Fig. 1. Schematic of spherulite's deformation in tension. Details of lamellar deformation in the polar part (A), under the angle $45^{\circ}(\mathrm{B})$ and in the equatorial part of the spherulite $(\mathrm{C})$ are presented.

Fig 2. The stress-strain dependence for HDPE sample deformed at the strain rate of $5 \% / \mathrm{min}$. Strobl's characteristic points of deformation [18] are marked as A-D.

Fig 3. Mechanical properties of selected polymers in tension (a) and related volume changes (b).

Fig 4. Deformed spherulite of polypropylene observed by SEM. The direction of deformation was horizontal. A - polar fan, B- equatorial area, C - diagonal, shear area, without cavities. $\mathrm{SD}$ - strain direction.

Fig. 5. Engineering stress-strain curve for injection molded HDPE and SAXS patterns registered for skin and core of sample (top). The morphology of skin and core is shown on SEM photographs (right). This figure is based on the data from the studies described in [41]. Fig 6. The photography of deformed HDPE sample and SAXS patterns, as registered in situ by applying synchrotron radiation. Arrows indicate the places where patterns were registered, the numbers show local strain. Scattering on voids is clearly visible for strains of 0.6 and 3.0, and some traces are observed for the strain of 0.15 .

Fig. 7. SAXS patterns for PP samples deformed to engineering strain of $25 \%$ at different strain rates: a) non deformed, b) $5 * 10^{-6} \mathrm{~s}^{-1}$, c) $0.8^{*} 10^{-5} \mathrm{~s}^{-1}$, d) $1.6^{*} 10^{-4} \mathrm{~s}^{-1}$. 